\title{
Relation between Heart Rate and Energy Expenditure in the Newborn
}

\author{
PHILIPPE CHESSEX, BRIAN L. REICHMAN, GASTON J. E. VERELLEN, GUY PUTET, JOHN M. \\ SMITH, TIBOR HEIM, AND PAUL R. SWYER ${ }^{(42)}$ \\ Departments of Paediatrics and Medical Engineering, University of Toronto and the Research Institute, The Hospital \\ for Sick Children, Toronto, Ontario, Canada
} \begin{abstract}
Summary
This study defines the relationship between heart rate and metabolic rate in newborn infants and evaluates the accuracy of prediction of metabolic rate from heart rate. Continuous measurements of oxygen uptake, $\mathrm{CO}_{2}$ production, respiratory quotient, and cumulative heart rate were performed using computerized, open-circuit indirect calorimetry and on-line electrocardiogram monitoring over periods of 1 to $24 \mathrm{hr}$ (mean $4.5 \mathrm{hr}$ ). Metabolic rate was calculated from the individual oxygen uptake and respiratory quotient. Thirty-five studies were performed in 16 infants (birthweight 0.75 to $3.1 \mathrm{~kg}$; gestational age, 26 to $42 \mathrm{wk}$; mean \pm S.D. age at study, $26.5 \pm 15.7$ days; study weight, $1.78 \pm 0.5 \mathrm{~kg}$ ). Metabolic rate $(\mathrm{cal} / \mathrm{kg} \cdot \mathrm{min})$ and heart rate (beats $/ \mathrm{min})$ were compared minute by minute ( 8269 measurements) and showed a close third degree polynomial relationship for heart rates of 110 to $230 / \min \left(y=-0.0000291 x^{3}+0.01685 x^{2}-2.93 x+197 ; r=0.99\right.$; $P<0.001$ ); however, at heart rates above 140 beats $/ \mathrm{min}$, a linear relationship was found $(r=0.997 ; P<0.001)$. From cumulated heart rate measurements, factors defining metabolic rate per heart beat were also determined: for each beat $51.8 \pm 6.8 \mu \mathrm{l}$ of oxygen/ $\mathrm{kg}$ are consumed and $0.258 \pm 0.03 \mathrm{cal} / \mathrm{kg}(1.1 \mathrm{~J} / \mathrm{kg})$ are expended. Despite the wide variation in birthweight, gestational age, method of feeding, and clinical characteristics, there was a remarkable consistency in the heart rate-metabolic rate relationships.
\end{abstract}

A further 10 studies were performed in a similar group of infants to assess the predictive value of the previously defined relationships and showed a mean percentage deviation of $5.7 \pm 4 \%$ from the measured value.

We conclude that in the varied group of newborns studied, heart rate correlates closely with metabolic rate and that cumulative heart rate measurements enable the estimation of metabolic rate in newborn infants. This provides a method of monitoring energy expenditure and caloric requirements over long periods.

\section{Speculation}

The "heart rate-metabolic rate" relationship defined in this paper, could offer a simple method of estimating energy expenditure and, hence, energy requirements for newborn infants.

The Fick principle defines the cardiac output (heart rate $\times$ stroke volume) as the ratio of oxygen consumption $\left(\dot{\mathrm{V}}_{2}\right)$ on arteriovenous $\mathrm{O}_{2}$ difference (24) and suggests a possible relation between heart rate and $\dot{\mathrm{V}} \mathrm{O}_{2}$. The estimation of $\dot{\mathrm{V}} \mathrm{O}_{2}$ or energy expenditure from heart rate measurements has been evaluated in adults $(1,5,6,8,18)$ and children $(4,9,10,17,30)$. This relationship has to our knowledge not been described in newborns and premature infants. Because of the complexity of the present techniques for assessment of metabolic rate (21), long-term studies are difficult to undertake. Evaluation of energy expenditure in this group of infants is important to determine optimal energy requirements. The ability to estimate metabolic rate by continuous mea- surement of heart rate would allow simple continuous monitoring of energy metabolism with the least possible interference with the infants' environmental and behavioural patterns. This study was designed to verify and define the "heart rate-metabolic rate" (HR$\mathrm{MR}$ ) relationship in newborn infants and to evaluate its predictability.

\section{MATERIALS AND METHODS}

\section{SUBJECTS}

Thirty-five studies were performed in 16 newborn infants of birthweight (mean \pm S.D.) $1.55 \pm 0.65 \mathrm{~kg}$ (range, 0.75 to $3.1 \mathrm{~kg}$ ) and gestational age $32 \pm 5 \mathrm{wk}$ (range, 26 to $42 \mathrm{wk}$ ). The mean age at the time of study was $26.5 \pm 15.7$ days (range, 5 to 61 days) and the mean weight at the time of study was $1.78 \pm 0.5 \mathrm{~kg}$ (range, 0.96 to $2.75 \mathrm{~kg}$ ). The infants studied fell into two groups: 10 orally fed, very low birthweight, premature infants (birthweight, $1.18 \pm$ $0.2 \mathrm{~kg}$; weight at study, $1.46 \pm 0.2 \mathrm{~kg}$ ) and six larger babies. receiving total parenteral nutrition after abdominal surgery (birthweight, $2.12 \pm 0.7 \mathrm{~kg}$; weight at study, $2.11 \pm 0.5 \mathrm{~kg}$ ). Analysis showed similar results in both groups, and they therefore have been combined. From these 35 studies, HR-MR relationships were defined. Despite the varied clinical nature of the patients studied (Table 1), the HR-MR correlation proved remarkably uniform.

Ten more studies were performed on a further six infants to assess the predictive value of the originally defined HR-MR relationships in a similar population of newborn infants. Informed parental consent was obtained for all studies.

\section{METHODS}

Energy expenditure was measured by continuous, computerized, on-line, open-circuit, indirect calorimetry $(14,21,25,32)$. The principles of the technique are shown in Figure 1. The infant is studied in an incubator maintained in the thermoneutral range as recommended by Hey (19). The infant's head is enclosed in an airtight perspex hood, and the iris diaphragm is lightly cinched around the neck, permitting air to enter only through the neck aperture. The hood is exhausted through a manifold at a constant rate precisely measured by a Fleisch pneumotachometer (Dynasciences, Blue Bell, PA). The exhaust air is passed through the measuring cells of a paramagnetic $\mathrm{O}_{2}$ analyser (Taylor Servomex OA184, Crowborough, England) (15), and an infrared $\mathrm{CO}_{2}$ analyser (Beckman LB2, Palo Alto, CA). A sample from the air in the incubator is simultaneously and similarly analysed. The difference in $\mathrm{O}_{2}$ and $\mathrm{CO}_{2}$ concentration between air entering and air leaving the hood (approximately $0.5 \%$ ) is continuously recorded together with the flow rate $(\sim 1$ liter $/ \mathrm{kg} \cdot \mathrm{min})$. By applying the Fick principle and correcting for gas volume changes due to variation in respiratory quotients $(\mathrm{R})$ from 1.0 and reducing resulting volumes to standard temperature and pressure dry, the $\mathrm{VO}_{2}$ and $\mathrm{VCO}_{2}$ are calculated as a function of time (25). During the study, core temperature, skin temperature at six sites, and environmental 
temperature were recorded, and changes in activity and sleep state were continuously monitored using the 10-point Brück scale (12).

Heart rate was simultaneously measured by a neonatal cardiac monitor (Hewlett Packard 78213, Waltham, MA) and recorded on line both as a mean heart rate for each minute and a cumulative total of heart beats over the whole study period. Metabolic rate was calculated from the caloric value of $\mathrm{O}_{2}$ for the specific measured R (26). Infants were studied for periods of 1 to $24 \mathrm{hr}$ (mean, $4.5 \mathrm{hr}$ ), and a total of 8269 minute-by-minute simultaneous measurements of $\dot{\mathrm{V}} \mathrm{O}_{2}, \dot{\mathrm{V}} \mathrm{CO}_{2}, \mathrm{R}$, metabolic rate, and heart rate were recorded during periods of quiet and active sleep as well as awake states and periods of crying.

\section{ANALYSIS OF DATA}

Changes in heart rate and $\mathrm{VO}_{2}$ in an individual study over a $30-$ min period are shown in Figure 2. The changes in metabolic rate follow fluctuations in heart rate by $3 \mathrm{~min}$. Spady et al. (29) suggested that this was due to the response time of the instrument. We found the phase lag to be related to the rate of flow of the gases through the system. To enable analysis of minute-by-minute simultaneous heart rate and metabolic rate readings, it was necessary in each case to apply a specific phase lag correction

Table 1. Clinical parameters of infants at time of study

\begin{tabular}{lcc}
\hline \multicolumn{1}{c}{ Clinical parameters } & $\begin{array}{c}\text { No. of infants } \\
(n=16)\end{array}$ & $\begin{array}{c}\text { No. of studies } \\
(n=35)\end{array}$ \\
\hline Birthweight $\leq 1000 \mathrm{~g}$ & 4 & 7 \\
Small for gestational age $^{\text {Anemia }}{ }^{1}$ & 2 & 6 \\
Blood transfusion before study $^{2}$ & 3 & 5 \\
$\mathrm{FiO}_{2}>0.21$ & 3 & 6 \\
Patent ductus arteriosus $_{\text {Ventricular septal defect }}$ & 5 & 7 \\
Drugs & 5 & 10 \\
$\quad$ Aminophylline & 1 & 1 \\
Digoxin & 3 & \\
\hline
\end{tabular}

'Anemia defined by hemoglobin <1 S.D. of normals for age (22).

${ }^{2}$ Replacement of $>50 \%$ of blood volume. depending on the flow rate used in that study. When heart beats and metabolic rates were cumulated over a considerable period, this short lag in response time was of no importance and could be ignored in calculating the relationship.

The data were evaluated as follows.

Minute-by-Minute Measurements. From the minute-by-minute measurements of heart rate (beats/min) and metabolic rate (cal/ $\mathrm{kg} \cdot \mathrm{min}$ ) for all 35 studies combined ( 8269 measurements), regression analyses were performed to define the relationship between these variables. The data were analysed in 24 defined heart rate categories at intervals of 5 beats/min (111 to 115,116 to 120 , .... 226 to 230 beats $/ \mathrm{min}$ ), and a regression was constructed of the mean metabolic rate with the corresponding mean heart rate.

Cumulative Heart Rate Measurements. From the cumulative heart rate and the mean $\dot{\mathrm{VO}}_{2}$ or mean metabolic rate recorded over the whole period of the study, the following factors were calculated for each study:

Oxygen uptake per heart beat $(\mu \mathrm{l} / \mathrm{kg} \cdot$ beat $)$

$=$ mean $\dot{\mathrm{VO}}_{2} \times$ duration of study $(\mathrm{min}) /$ cumulated heart beats

Energy expenditure per beat (cal/ $\mathrm{kg} \cdot$ beat)

$=$ mean metabolic rate

$\times$ duration of study $(\mathrm{min}) /$ cumulated heart beats

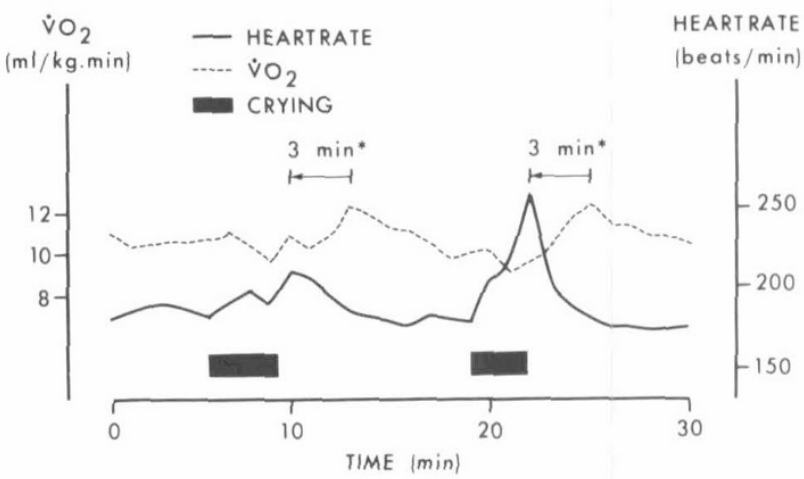

Fig. 2. An individual study of simultaneous variations in heart rate and $\dot{\mathrm{V}} \mathrm{O}_{2}$ showing a $3 \mathrm{~min}$ phase lag $\left(^{*}\right)$ due to the transit time of gaseous flow through the system.

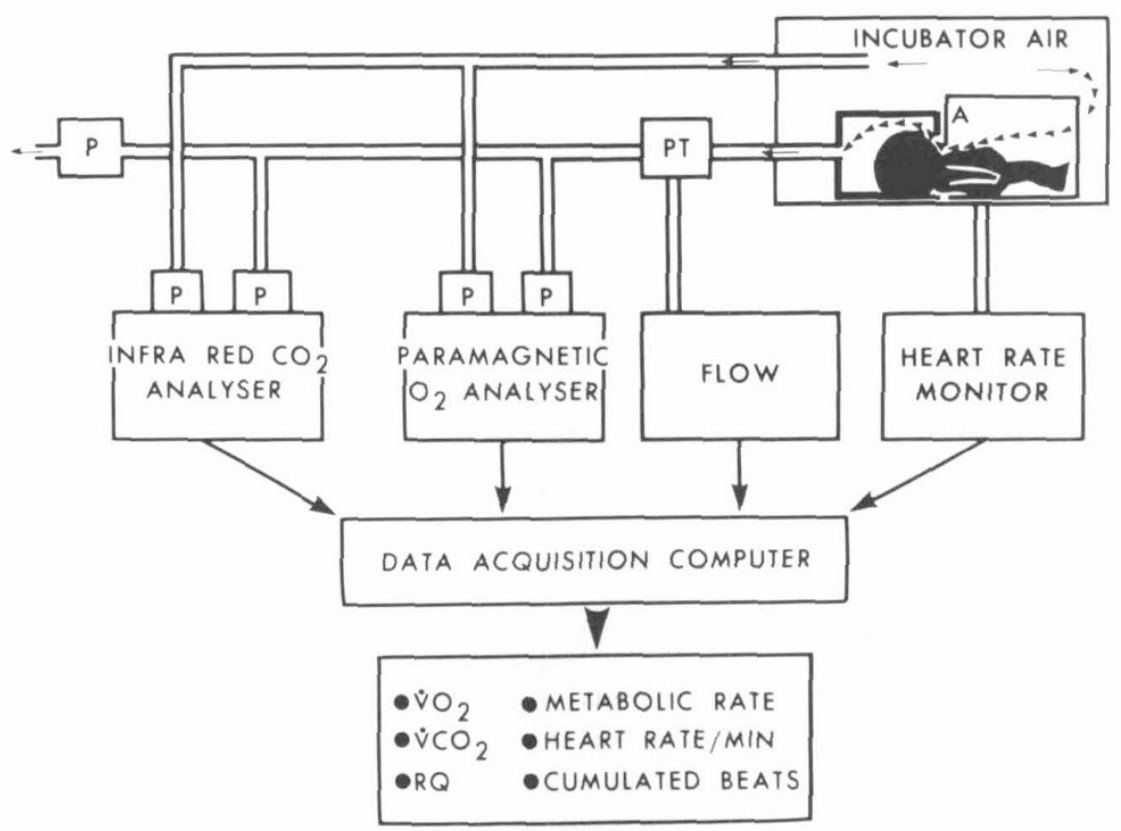

Fig. 1. Block diagram for continuous, open-circuit, computerized, indirect calorimetry coupled with heart rate monitoring. $A$, heat shield; $P$, pump; PT, pneumotachometer. 
RESULTS

\section{INDIVIDUAL STUDIES}

Regression analysis of the minute-by-minute results was performed for each infant. Figure 3 shows the computerized analysis of a single infant studied over $420 \mathrm{~min}$. Each point represents the metabolic rate and heart rate for a given minute. In 30 of 35 individual studies, a close linear regression (mean, $r=0.72$; range, 0.51 to $0.95 ; P<0.001$ ) was found between heart rate and metabolic rate. In 5 of 35 individual studies, the low and relatively constant heart rate prevented construction of an individual linear regression, but the MR-HR proportionality was preserved.

\section{GROUP STUDIES}

Minute-by-Minute Measurements. The heart rate frequency distribution for the 35 studies is shown in Figure 4. From this histogram, it is apparent that although the heart rates ranged from 110 to 230 beats $/ \mathrm{min}, 85 \%$ of heart rate measurements were above 140 beats $/ \mathrm{min}$. The mean heart rate of the infants studied was $154 / \mathrm{min}$.

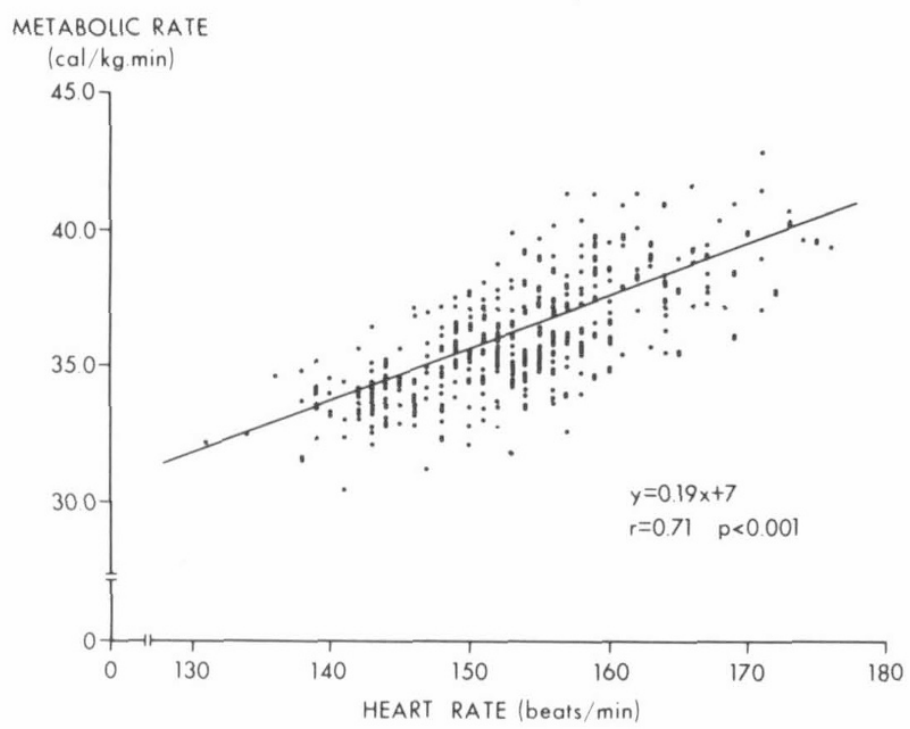

Fig. 3. Correlation of 420 individual measurements of heart rate (beats/min) and metabolic rate (cal/ $\mathrm{kg} \cdot \mathrm{min})$ in a single 7 -hr study.
The curve relating mean heart rate and mean metabolic rate \pm I S.D. is represented in Figure 5. The line of best fit for all points between 110 to 230 beats/min is a polynomial distribution to the third degree which is represented by the equation:

$$
y=-0.0000291 x^{3}+0.01685 x^{2}-2.93 x+197
$$

This correlation is highly significant $(r=0.99 ; P<0.001)$. From the mean \pm 1 S.D. metabolic rate measured for each heart rate group, a coefficient of variation of $11.5 \%$ (range, 4 to $16 \%$ ) was determined for this curve. Above a heart rate of $140 / \mathrm{min}$ (representing $85 \%$ of all measurements), there is a highly significant linear relationship between metabolic rate and heart rate:

$$
\mathrm{y}=0.29 \mathrm{x}-6.1(r=0.997 ; P<0.001)
$$

The flattening of the curve below 140 beats/min suggests that a resting metabolic rate is reached and can be estimated at $53 \mathrm{kcal} /$ $\mathrm{kg}$. day $(222 \mathrm{~kJ} / \mathrm{kg} \cdot$ day $)$ for this group of infants.

Estimation of Metabolic Rae per Heart Beat. From the cumula-

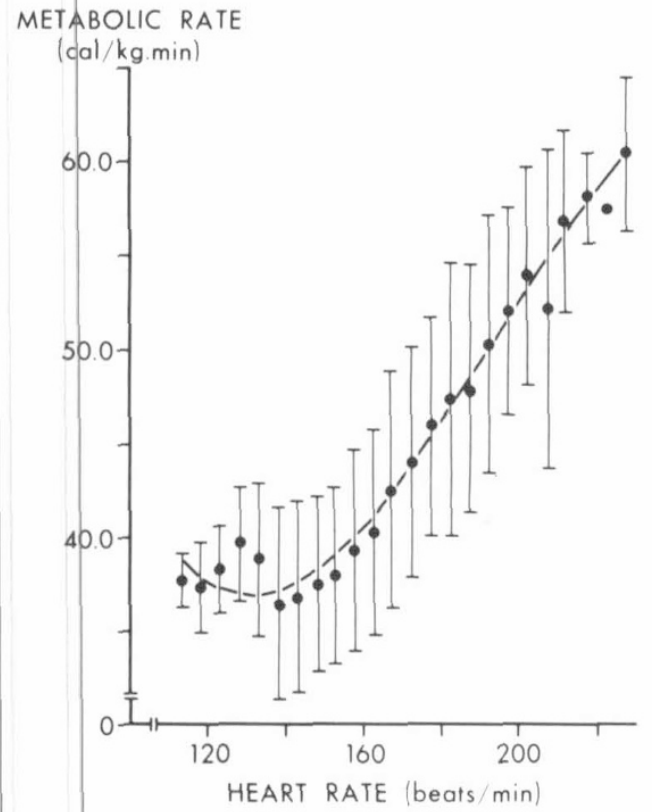

Fig. 5. Polynomial distribution relating mean heart rate and mean \pm 1 S.D. metabolic rate in 35 studies. $\left(y=-0.0000291 x^{3}+0.01685 x^{2}-2.93 x\right.$ $+197 ; r=0.99 . P<0.001)$.

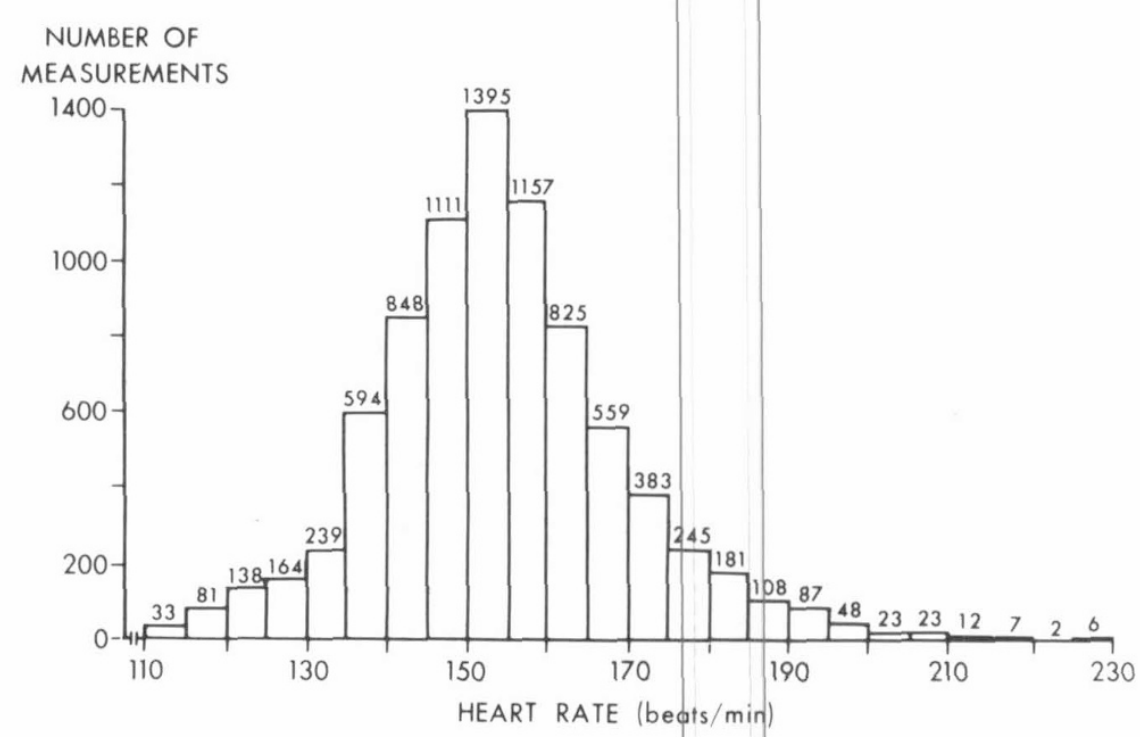

Fig. 4. Heart rate frequency distribution of 8269 points from 35 studies. Each heart rate category represents a five-beat interval. 
tive heart rate measurements and mean metabolic rate over the whole study, oxygen uptake per heart beat and metabolic rate per heart beat factors were calculated for individual studies, showing very small interindividual variation. From these individual results, the mean \pm S.D. metabolic rate per heart beat was calculated for the whole group:

$$
\text { Oxygen uptake per heart beat }=51.8 \pm 6.8 \mu \mathrm{l} \mathrm{O} 2 / \mathrm{kg}
$$

Energy expenditure per beat $=0.258 \pm 0.03 \mathrm{cal} / \mathrm{kg}(1.1 \mathrm{~J} / \mathrm{kg})$

The relationship between heart rate and metabolic rate in this specific group of infants is constant with a coefficient of variation of $11.5 \%$. We considered several clinical characteristics which may affect the individual HR-MR relationship, such as the weight and age of the infant, the presence of a shunt through a patent ductus arteriosus, anemia (22), blood transfusions, acidosis, drug therapy and type of feeding (see Table 1). The constant factors were apparently not influenced by these clinical features in this group of infants.

\section{PREDICTIVE VALUE OF HR-MR RELATIONSHIPS}

To assess the ability to predict individual energy expenditure by measurement of heart rate, 10 additional studies were performed in a similar population of newborns for periods of $5.5 \pm$ $1.5 \mathrm{hr}$ (range, 3 to $7.5 \mathrm{hr}$ ) with continuous monitoring of heart rate during the metabolic study. Using both the polynomial relationship and the constant energy expenditure per heart beat factor determined from the 35 studies, an estimative error of predicting individual metabolic rate was obtained for these 10 additional studies. Figure 6 shows the previously defined polynomial distribution on which the additional measured metabolic rates and mean heart rates of these 10 studies are plotted. All measurements are within \pm I S.D. of the original curve, and the mean error of estimate is $5.6 \pm 4 \%$ (range, $-5 \%$ to $+14 \%$ ). Using the factor of $0.258 \mathrm{cal} / \mathrm{kg}$ per heart beat, the mean error of estimate was $5.7 \pm$ $4 \%$ (range, $-4 \%$ to $+11.5 \%$ ), and the predictive error was less than $10 \%$ in 8 of 10 studies. We have further corroboration of the consistency of the HR-MR relationship from a study in a newborn with congenital hyperthyroidism. His mean heart rate of 199 beats $/ \mathrm{min}$ and measured metabolic rate of $53 \mathrm{cal} / \mathrm{kg} \cdot \mathrm{min}$ fell on the upper end of our defined curve as shown in Figure 6.

In 14 infants, more than one study had been performed, enabling the evaluation of the intraindividual prediction of energy

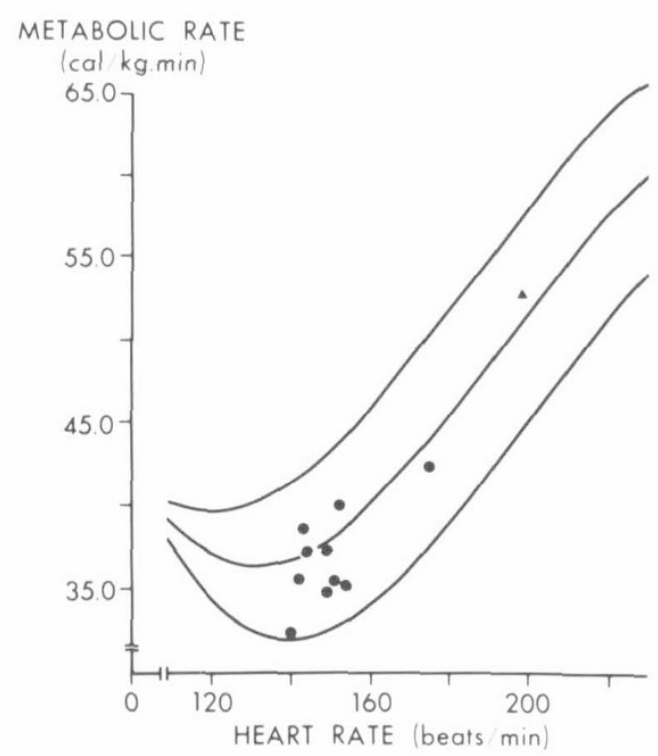

Fig. 6. Previously defined mean heart rate versus mean metabolic rate polynomial distribution (see Fig. 5) tested by 10 additional studies (-). All 10 fall within \pm 1 S.D. of the original distribution curve. Measured heart rate and metabolic rate in an infant with congenital hyperthyroidism ( $\mathbf{A})$. expenditure from a baby's own calibration factor $(\mathrm{cal} / \mathrm{kg} \cdot \mathrm{heart}$ beat) determined from the first study. In 19 studies, the intraindividual mean error of estimate was $7.3 \pm 5 \%$ (range, $-10 \%$ to $+20 \%$ ). By this approach, the predictive error was less than $10 \%$ in 15 of 19 studies. We found no influence of the clinical factors shown in Table 1, on the accuracy of prediction.

\section{DISCUSSION}

A simple but accurate estimate of the energy metabolism of newborn and premature infants is desirable to obtain an adequate guide to caloric intake. Total energy requirement in the newborn has two major components: firstly, metabolic energy expenditure, and secondly, the additional energy of nutrients stored as new tissue during growth. This paper describes a simple method of evaluating the first of these components. The second component is accessible by additional nutritional balance studies. The usual measurement of metabolic energy expenditure, however, requires cumbersome and complicated equipment, which may affect the infant's environmental and behavioural pattern and therefore is not practical as a routine clinical investigation. In adults, Benedict (3) in 1907 correlated changes in pulse rate with changes in energy expenditure, and the estimation of metabolic rate from heart rate has since been used in various clinical conditions $(4,9,10,17,29$, $35)$ as well as in sports $(13,20,33)$ and occupational medicine (1, $30,34)$. We now have tested the hypothesis that neonatal heart rate will provide an accurate measurement of energy expenditure.

Minute-by-minute measurements of heart rate and metabolic rate showed a significant correlation in individual infants in whom wide fluctuations in heart rate were present. The calibration of increasing heart rate with metabolic rate has been obtained by others in children and adults by applying increasing workloads using treadmills (30), simulated rowing (20), bicycle riding (13, 33 ), and other forms of exercise (1). We were not able to impose such variations in activity on our patients. An individual calibration curve was obtained when heart rate fluctuations secondary to changes in sleep state, increased activity, or crying occurred spontaneously.

The evaluation of over 8000 minute-by-minute results from the 35 studies combined showed a highly significant third degree polynomial relationship of heart rate to metabolic rate (Fig. 5) with a significant linear relationship above 140 beats per min and a flattening of the curve below this value. Viteri et al. (34) and Åstrand et al. (2) have shown similar curves in adults, with a flattening in the lower heart rate range $(<80$ beats $/ \mathrm{min})$ under resting conditions.

This relationship evokes a number of interesting theoretical considerations. Dynamic cardiac studies in adults have shown that stroke volume attains almost maximal values at a work load corresponding to $40 \%$ of $\dot{\mathrm{VO}}_{2} \max$ (33). Thus, with an increase in work load above this level, further increase in cardiac output is predominantly dependent on increasing heart rate. Vanfraechem (33) concludes also that in exercising adults the restricted values of stroke volume at high work loads is responsible for the high level of heart rate. Our studies indicate that in newborn infants, at heart rates above 140 beats/min, corresponding to the linear part of the curve, cardiac output is dependent upon heart rate. Conversely, in the resting state corresponding to the flattened part of the curve, changes in cardiac output are dependent upon changes in stroke volume, explaining the variability of heart rate for a relatively constant metabolic rate in this part of the curve.

These findings can be explained physiologically on the basis of previous studies. Friedman (16) has shown in the developing heart that the contractile mass of the fetal myocardium is reduced, with a decrease in isometric force development and a reduced compliance in cardiac muscle. In addition, both pharmacologic and histochemical observations show incomplete sympathetic innervation in the fetal and early newborn heart. Rudolph (28) using a chronic fetal lamb preparation showed that cardiac output of the fetus is very dependent on heart rate and that the fetal ventricle was limited in its capacity to increase or maintain stroke volume 
in the face of an increase in afterload. Conversely, under resting conditions, changes in cardiac output in premature and full-term newborn infants appear to be predominantly dependent upon stroke volume changes $(11,31)$.

The use of heart rate measurements for the prediction of metabolic rate has been assessed by others using either individual or group regressions. Evaluation of individual regressions in children $(4,29,30)$ and adults $(5,8,18,35)$ required initial calorimetric measurements to determine the individual's own HR-MR relationship. Bradfield (7) concludes that this technique is more accurate in predicting individual energy expenditure than determining a common regression for a group of subjects. In a number of studies $(7,9,10)$, he found a coefficient of variation of up to $27 \%$ in the prediction of energy expenditure. Payne et al. (27) have used previously published data to determine regressions between heart rate and metabolic rate, taking age, sex, and state of training into account in an attempt to improve the accuracy of the metabolic rate prediction. From their results, it is apparent that the variation in prediction of energy expenditure is very large. In our study, the coefficient of variation of both the group regression line and the metabolic rate per heart beat factor is $11.5 \%$. This figure is low in view of the varied clinical features of the infants studied (Table 1). Conditions such as anemia, patency of the ductus arteriosus, drug therapy (23), varying body weight, and postnatal age could not be shown systematically to influence the HR-MR relationship. This might suggest that metabolic rate (or oxygen demand) required in a certain set of circumstances is satisfied by the appropriate cardiac output and therefore, heart rate. Any increase in oxygen demand (e.g., from increased myocardial work in left $\rightarrow$ right shunting through a ductus arterious) would result in a concomitant increase in both metabolic rate and heart rate, and the constancy of the HR-MR relation is preserved. However, it remains a possibility for future study that these and other clinical features could be responsible collectively and/or individually for the $11.5 \%$ coefficient of variation exhibited by the infants in our study.

The predictive value of our group relationship was assessed using both the polynomial curve and the constant calibration factor of $0.258 \mathrm{cal} / \mathrm{kg}$ per heart beat in 10 additional studies. Furthermore, we analyzed the predictive value of each individual's HR-MR relationship in 19 repeat studies. Our mean error of estimation from group relationships $(5.7 \%)$ was smaller than when using an individual's energy expenditure derived from his own calibration factor $(7.3 \%)$.

The greater accuracy of prediction of energy expenditure from heart rate measurements in our newborn infants compared with adults $(7,27)$ is probably due to the intrinsic properties of the newborn heart as discussed, as well as the relatively constant body constitution, activity state, thermal environment, energy intake, and growth rate in these infants. Our results indicate that the simple prolonged measurement of cumulative heart rate using commercially available heart rate counters and a constant metabolic factor of $0.258 \mathrm{cal} / \mathrm{kg}$ per heart beat enables estimation of an infant's energy expenditure within acceptable limits of $10 \%$ in most infants. The incorporation of suitable electronic circuitry to a heart rate counter could convert the cumulative heart rate to the appropriate metabolic rate (36).

\section{CONCLUSION}

A correlation has been developed which enables prediction of metabolic energy expenditure from heart rate with a coefficient of variation of $11.5 \%$. This relationship can be used as a simple method for prediction of metabolic energy expenditure from heart rate in the newborn. Excess metabolizable energy intake over this predicted metabolic energy expenditure is utilizable for tissue deposition.

\section{REFERENCES AND NOTES}

1. Acheson, K. J., Campbell, I. T., Edholm. O. G., Miller, D. S., and Stock, H. J. The measurement of daily energy expenditure - an evaluation of some techniques. Am. J. Clin. Nutr., 33: 1155 (1980).
2. Ästrand, P., Cuddy, T. E., Saltin. B., and Stenberg, J.: Cardiac output during submaximal and maximal work. J. Appl. Physiol., 19: 269 (1964).

3. Benedict, F. G.: Influence of inanition on metabolism. Carnegie Inst. Wash. Publ., 77 (1907)

4. Berg, K.: Heart rate telemetry for evaluation of the energy expenditure of children with cerebral palsy. Am. J. Clin. Nutr., 24: 1438 (1971).

5. Booyens, J., and Hervey, G. R.: The pulse rate as a means of measuring metabolic rate in man. Can. J. Biochem. Physiol., 33: 1301 (1960).

6. Bradfield, R. B., Huntzicker, P. B., and Fruenan, G. J.: Simultaneous comparison of respirometer and heart-rate telemetry techniques as measures of human energy expenditure. Am. J. Clin. Nutr., 22: 696 (1969).

7. Bradfield, R. B., Huntzicker, P. B., and Fruehan. G. J.: Errors of group regressions for prediction of individual energy expenditure. Am. J. Clin. Nutr., 23: 1015 (1970).

8. Bradfield, R. B.: A technique for determination of usual daily energy expenditure in the field. Am. J. Clin. Nutr., 24: 1148 (1971).

9. Bradfield, R. B., Paulos, J., and Grossman, L.: Energy expenditure and heart rate of obese high school girls. Am. J. Clin. Nutr., 24: 1482 (1971).

10. Bradfield, R. B., Chan, H., Bradfield. N. E., and Payne. P. R.: Energy expenditures and heart rates of Cambridge boys at school. Am. J. Clin. Nutr.. 24: 1461 (1971).

11. Brady, J. P., and Rigatto, H.: Pulmonary capillary flow in the newborn infant: a new method using the plethysmograph and nitrous oxide. Pediatrics, 48: 207 (1971).

12. Brück, K., Parmelee, A. H., and Brück, M.: Neutral temperature range and range of "thermal comfort" in premature infants. Biol. Neonate, 4: 32 (1962).

13. Davies, C. T. M.: Limitations to the prediction of maximum oxygen intake from cardiac frequency measurements. J. Appl. Physiol., 24: 700 (1968).

14. Durnin, J. V. G. A.: Indirect calorimetry in man: a critique of practical problems. Proc. Nutr. Soc., 37: 5 (1978).

15. Ellis, F. R., and Nunn, J. F.: The measurement of gaseous oxygen tension utilizing paramagnetism; an evaluation of the Servomex OA 150 analyzer. $\mathrm{Br}$. J. Anaesth., 50: 569 (1968).

16. Friedman, W. F.: The intrinsic physiologic properties of the developing heart. In; W. F. Friedman, M. Lesch, E. H. Sonnenblick: Neonatal Heart Disease. pp. 21-49 (Grune \& Stratton: New York, 1973).

17. Gandra, Y. R., and Bradfield. R. B.: Energy expenditure and oxygen handling efficiency of anemic school children. Am. J. Clin. Nutr.. 24: 1451 (1971).

18. Goldsmith, R., Miller, D. S., Mumford, P., and Stock, M. J.: The use of longterm measurements of heart rate to assess energy expenditure. J. Physiol. (Lond.), 189: 35P (1966).

19. Hey, E.: The care of babies in incubators. In: D. Gairdner, D. Hull: Recent Advances in Pediatrics. Ed. 4. pp. 171-216 (Churchill. London. 1971).

20. Hagerman, F. C., Connors, M. C., Gault, J. A., Hagerman, G. R., and Polinski. W. J.: Energy expenditure during simulated rowing. J. Appl. Physiol., 45: 87 (1978).

21. Karlbeg, P.: Determination of standard energy metabolism (basal metabolism) in normal infants. Acta Pediatr. Scand. 41: 67 (1952).

22. Klaus, M. H., and Fanaroff, A. A.: In: Care of the High Risk Neonate. Ed. 2, p. 401 (W. B. Saunders Co., Philadelphia (1979).

23. Krauss, A. N.. Milsap, R. L., and Auld, P. A. M.: Effect of theophylline on metabolic rate in premature infants. Am. Rev. Respir. Dis.. 121: 291 (1980).

24. Lees, M. H., Bristow, J. D.. Way. C.. and Brown, M.: Cardiac output by Fick principle in infants and young children. Am. J. Dis. Child., 114: 144 (1967).

25. Lister, G., Hoffman, J. I. E., and Rudolph. A. M.: Oxygen uptake in infants and children: a simple method of measurement. Pediatrics, 53: 656 (1974).

26. Lusk. G. (modified from Zuntz, N.. and Schumberg. H.): Basal metabolism standards. In: K. Diem: Scientific Tables. Ed. 6. p. 618 (Documenta Geigy. Montreal, 1961).

27. Payne, P. R., Wheeler, E. F., and Salvosa, C. B.: Prediction of daily energy expenditure from average pulse rate. Am. J. Clin. Nutr., 24: 1164 (1971).

28. Rudolph. A. M.: The fetal circulation. In: Congenital Diseases of the Heart. pp. 1-16 (Year Book Medical Publishers, Chicago, 1974)

29. Spady, D. W.. Payne. P. R.. Picou, D.. and Waterlow, J. C.: Energy balance during recovery from malnutrition. Am. J. Clin. Nutr.. 29: 1073 (1976).

30. Spady, D. W.: Total energy expenditure of healthy, free ranging school children. Am. J. Clin. Nutr., 33: 766 (1980)

31. Stocks, J., Costeloe, K.. Winlove. C. P.. and Godfrey, S.: Measurement of pulmonary capillary blood flow in infants by plethysmography. J. Clin. Invest.. 59: 490 (1977).

32. Swyer, P. R., Putet. G., Smith, J. M., and Heim. T.: Energy metabolism and substrate utilisation during total parenteral nutrition in the newborn. In: L. Stern, W. Oh, B. Friis-Hansen: Intensive Care in the Newborn, Vol. Il. pp. 307-316 (Masson, Publishing USA. Inc.. New York. 1978).

33. Vanfraechem, J. H. P.: Stroke volume and systolic time interval adjustments during bicycle exercise. J. Appl. Physiol., 46: 588 (1979).

34. Viteri. F. E.. Torun, B.. Galicia, J. C., and Herrera, E. I.: Determining energy costs of agricultural activities by respirometer and energy balance techniques. Am. J. Clin. Nutr., 24: 1418 (1971).

35. Warnold. I., and Lenner. R. A.: Evaluation of the heart rate method to determine the daily energy expenditure in disease. A study in juvenile diabetes. Am. J. Clin. Nutr., 30: 304 (1977).

36. Patent pending.

37. Dr. Philippe Chessex is a Fellow of the Medical Research Council of Canada

38. Dr. Brian Reichman is a Fellow of the Research Institute of The Hospital for Sick Children, Toronto, Ontario.

39. Dr. Gaston Verellen held a N.A.T.O. Fellowship.

40. Dr. Guy Putet was a Fellow of the National Research Council of Canada. (Franco-Canadian Cultural Exchange). 
41. The authors wish to thank Dr. Paul N. J. Corey. Ph.D.. Associate Professor of the Department of Preventive Medicine and Biostatistics. University of Toronto. for his advice.

42. Requests for reprints should be addressed to: Dr. Paul R. Swyer. Chief. Division of Perinatal Medicine. The Hospital for Sick Children. Toronto, Ontario. Canada M5G IX8.
43. This research was supported in part by National Health and Welfare Canada Grant 6606-1482-40 and in part by a Grant from the Physicians Services, Inc., Toronto, Ontario, Canada.

44. Received for publication August 14, 1980.

45. Accepted for publication December 2. 1980.

Copyright (C) 1981 International Pediatric Research Foundation. Inc.

Printed in U.S.A. $0031-3998 / 81 / 1508-1077 \$ 02.00 / 0$ 